Supplement of Hydrol. Earth Syst. Sci., 25, 653-669, 2021

https://doi.org/10.5194/hess-25-653-2021-supplement

(c) Author(s) 2021. This work is distributed under

the Creative Commons Attribution 4.0 License.

(c) (1)

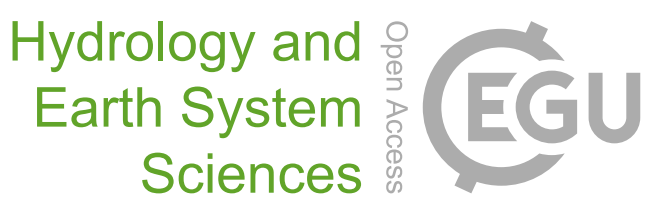

Supplement of

\title{
Modeling the response of soil moisture to climate variability in the Mediterranean region
}

Louise Mimeau et al.

Correspondence to: Yves Tramblay (yves.tramblay@ird.fr)

The copyright of individual parts of the supplement might differ from the CC BY 4.0 License. 


\section{Supplementary material}

\section{Observed data availability}

Table S1 shows the availability of observed precipitation, temperature, and soil moisture data for the 10 stations located in the french Mediterranean region. The period with available data ranges between 7 years (Pez) and 10 years (Lez, Mou, Nar). The precipitation and temperature datasets have very few missing data that needed to be reconstructed (less than $1.5 \%$ ) in

5 order to be used as forcing data for the soil moisture model. Observed soil moisture were used as validation for the soil model calibration. Some stations have a large amount of missing data (45\% for Barn station and $12 \%$ for Lez and Mej stations). Periods with missing soil moisture data were not taken into account during the calibration process, which reduces the total period of calibration and may affect the calibration of the stations with most missing data.

\begin{tabular}{llllll} 
& & & \multicolumn{3}{c}{ Missing data [\%] } \\
\cline { 4 - 6 } Code & From & To & Precipitation & Temperature & Soil moisture \\
\hline Barn & $14 / 11 / 2008$ & $31 / 12 / 2016$ & $1.5 \%$ & $1.5 \%$ & $45 \%$ \\
Cab & $14 / 11 / 2008$ & $31 / 12 / 2016$ & $0.9 \%$ & $1.2 \%$ & $2.2 \%$ \\
Gra & $13 / 12 / 2008$ & $31 / 12 / 2016$ & $0.7 \%$ & $0.3 \%$ & $2.6 \%$ \\
Lez & $01 / 01 / 2007$ & $31 / 12 / 2016$ & $0.6 \%$ & $1.2 \%$ & $12.6 \%$ \\
Mej & $09 / 12 / 2008$ & $31 / 12 / 2016$ & $1.1 \%$ & $0.7 \%$ & $12.1 \%$ \\
Mou & $01 / 01 / 2007$ & $31 / 12 / 2016$ & $1.0 \%$ & $0.3 \%$ & $3.1 \%$ \\
Nar & $01 / 01 / 2007$ & $31 / 12 / 2016$ & $0.2 \%$ & $0.2 \%$ & $3.2 \%$ \\
Pez & $11 / 12 / 2008$ & $18 / 04 / 2016$ & $0.6 \%$ & $0.6 \%$ & $1.5 \%$ \\
Pra & $11 / 12 / 2008$ & $31 / 12 / 2016$ & $0.3 \%$ & $0.4 \%$ & $3.7 \%$ \\
Vil & $15 / 12 / 2008$ & $31 / 12 / 2016$ & $0.7 \%$ & $0.5 \%$ & $4.4 \%$
\end{tabular}

Table S1. Periods of observed data and percentage of missing data for each station. 


\begin{tabular}{|c|c|c|c|c|c|c|c|c|c|c|}
\hline & Barn & $\mathrm{Cab}$ & Gra & Lez & Mej & Mou & Nar & Pez & Pra & Vil \\
\hline & \multicolumn{10}{|c|}{ Calibration on the total period } \\
\hline$K_{s}\left(\mathrm{~mm} \cdot \mathrm{hr}^{-1}\right)$ & 38.1 & 34.3 & 35.9 & 23.1 & 28.8 & 36.2 & 51.1 & 14.6 & 59.6 & 6.9 \\
\hline$m$ & 17.6 & 15.6 & 10.9 & 14.1 & 16.4 & 23.0 & 15.9 & 12.8 & 11.89 & 38.2 \\
\hline$K_{c}$ & 1.17 & 1.43 & 1.74 & 1.22 & 1.81 & 0.94 & 1.26 & 1.99 & 1.32 & 1.63 \\
\hline \multirow[t]{2}{*}{ NSE } & .76 & 0.77 & 0.93 & 0.85 & 0.9 & 0.63 & 0.91 & 0.789 & 0.65 & 0.9 \\
\hline & \multicolumn{10}{|c|}{ Calibration on the first sub-period } \\
\hline$K_{s}\left(\mathrm{~mm} \cdot \mathrm{hr}^{-1}\right)$ & 26.9 & 52.0 & 56.2 & 41.6 & 24.6 & 22.5 & 52.0 & 24.0 & 61.9 & 22.6 \\
\hline$m$ & 17.8 & 15.8 & 11.3 & 15.4 & 14.7 & 17.8 & 17.5 & 21.0 & 10.5 & 40.0 \\
\hline$K_{c}$ & 1.28 & 1.49 & 1.95 & 1.30 & 1.76 & 1.02 & 1.31 & 1.86 & 1.31 & 1.63 \\
\hline \multirow[t]{2}{*}{ NSE } & 6 & 0.72 & 0.86 & 0.87 & 0.80 & 0.69 & 0.87 & 0.31 & 0.64 & 0.87 \\
\hline & \multicolumn{10}{|c|}{ Calibration on the second sub-period } \\
\hline$K_{s}\left(\mathrm{~mm} \cdot \mathrm{hr}^{-1}\right)$ & 29.6 & 23.7 & 43.9 & 40.8 & 45.6 & 77.4 & 43.1 & 6.4 & 71.4 & 2.7 \\
\hline$m$ & 23.2 & 17.1 & 11.3 & 14.8 & 18.9 & 22.4 & 13.5 & 5.5 & 13.0 & 39.9 \\
\hline$K_{c}$ & 1.09 & 1.42 & 1.53 & 1.11 & 1.87 & 1.32 & 1.19 & 1.97 & 1.31 & 1.56 \\
\hline NSE & 0.71 & 0.75 & 0.87 & 0.78 & 0.91 & 0.04 & 0.912 & 0.60 & 0.57 & 0.86 \\
\hline
\end{tabular}

Table S2. Calibrated parameters of the SM model and NSE validation values while calibrating on the total period, the first and second sub-periods of the in situ data series.

\begin{tabular}{llll}
\hline Nom_station & soil class USDA & USDA range of $K_{s}$ & Calibrated $K_{s}$ \\
\hline Bar & Sandy loam & $51-152$ & 38 \\
Cab & Loam & $15-51$ & 34 \\
Gra & Sandy loam & $51-152$ & 36 \\
Lez & Loam & $15-51$ & 23 \\
Mej & Loam & $15-51$ & 29 \\
Mou & Clay loam & $5-15$ & 36 \\
Nar & Clay & $2-5$ & 51 \\
Pez & Loam & $15-51$ & 15 \\
Pra & Clay loam & $5-15$ & 60 \\
Vil & Sandy loam & $51-152$ & 7
\end{tabular}

Table S3. Range of hydraulic conductivity values (min and max) based on soil class (Angerer et al., 2014) 


\section{NSRP model calibration}

Figure S1 shows the values of the NSRP model parameters after calibration. The calibration is performed independently for each month, which explains why the parameter values are not always continuous one month from another, and why some parameters reach high values ( $\xi$ parameter value in August in Barn station for instance). The comparison between the observed 5 and simulated hourly rainfall intensities (Fig S2) as well as the comparison between observed and simulated annual maximum intensities (Fig S3) show that the calibrated NSRP model represents correctly the distribution of rainfall intensities and does not generate aberrant values.
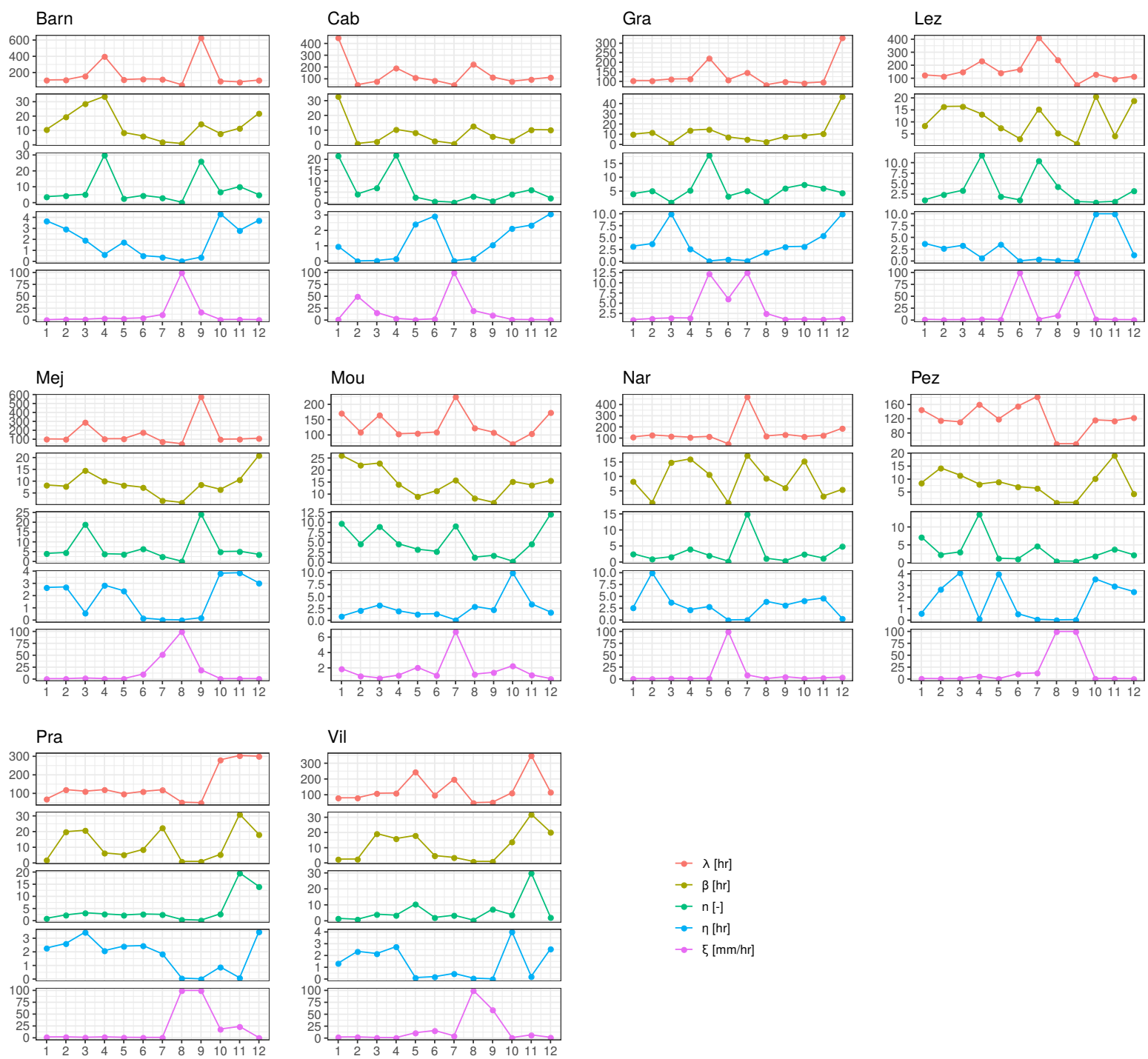

Figure S1. Monthly values of NSRP calibrated parameters. 


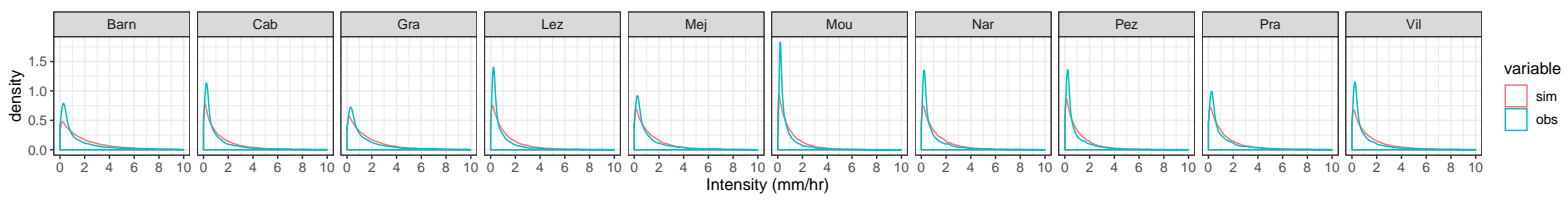

Figure S2. Density plot of observed (green) and simulated (red) hourly rainfall intensities.

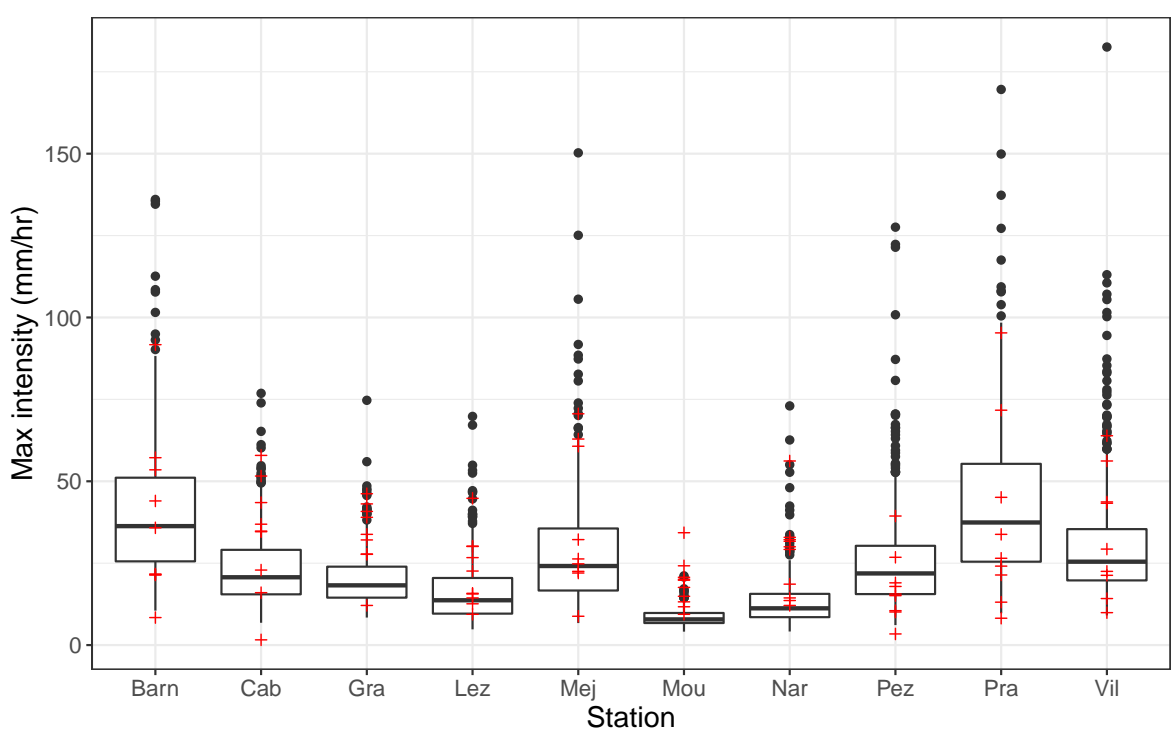

Figure S3. Annual maximum rainfall intensities (red crosses: observed, boxplot: simulated with NSRP model). 


\section{Complete results of sensitivity of extreme soil moisture to precipitation and temperature changes}

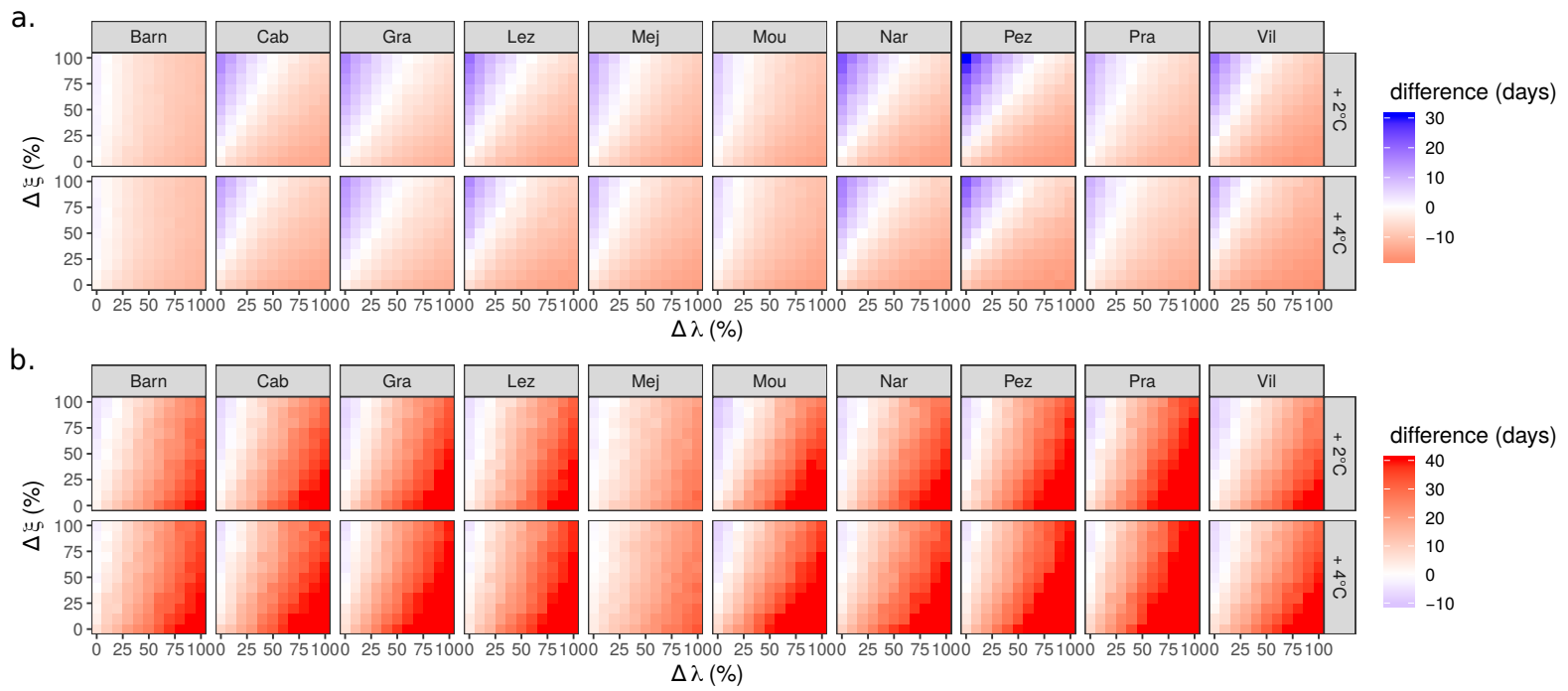

Figure S4. Sensitivity of the annual number of days with saturated soil (i.e. with soil moisture above the observed 95th percentile) according to changes in precipitation intensity (y axis), precipitation intermittence (x axis) and temperature. b. Sensitivity of the annual number of days under drought conditions (i.e. with soil moisture below the observed 5th percentile) 


\section{References}

Angerer, J. P., Bizimana, J.-C. B., and Alemayehu, S.: Reducing Risk in Pastoral Regions: The Role of Early Warning and Livestock Information Systems, Revista Científica de Produção Animal, 15, 9-21, 2014. 